\title{
Empty Gonometa postica cocoons function as nest sites and shelters for arboreal ants
}

Morgan Jade Raath ${ }^{1, *}$, Peter Christiaan le Roux ${ }^{1}$, Ruan Veldtman ${ }^{2}$, Heather Campbell ${ }^{3}$, Isabelle Patricia Rita Buyens ${ }^{1}$ and Michelle Greve ${ }^{1}$

\footnotetext{
${ }^{1}$ Department of Plant and Soil Sciences, University of Pretoria, Pretoria 0002, South Africa

${ }^{2}$ South African National Biodiversity Institute, Kirstenbosch Research Centre, Private Bag X7, Claremont, 7735, South Africa

${ }^{3}$ Department of Zoology and Entomology, University of Pretoria, Pretoria 0002, South Africa
}

*Corresponding author: Morgan J. Raath

Postal address: Department Plant and Soil Sciences, University of Pretoria, Private Bag X20, Hatfield 0028, South Africa

Email address: morganj.r@hotmail.com

Telephone number: +27834680043

\section{Highlights}

- Arboreal ants of different species were observed sharing trees and cocoons.

- Ants prefer wider cocoons containing small holes in trees containing scale insects.

- Ant abundance was lower in cocoons occupied by other invertebrates. 


\section{ABSTRACT}

Arboreal ants use a variety of plant structures as nesting sites, but may also nest in structures created by arboreal ecosystem engineers. We observed, for the first time, ants using empty cocoons of the economically important silk moth species, Gonometa postica, as shelter and nesting sites. Individual trees and individual cocoons were occupied predominantly by one dominant ant species, although in some cases by co-occurring ant species. Ant abundance and occurrence were positively related to cocoon size and the presence of scale insects on branches of the trees, and negatively influenced by cocoon occupancy by other invertebrates. Ants also preferred cocoons containing only small parasite holes as opposed to cocoons containing large moth emergence holes, suggesting that ants select cocoons based on cocoon characteristics. Further, these results reveal that other arboreal invertebrates appear to benefit from cocoon production. Empty cocoons could be functioning as nest sites and shelters for arboreal invertebrates, and they could create favourable habitats for other invertebrates on Vachellia erioloba. Therefore, G. postica acts as an autogenic ecosystem engineer and current silk harvesting practices, which partly rely on harvesting empty G. postica cocoons, may have potential local and large-scale implications for inter-specific interactions in these arboreal systems.

Keywords: Biogenic arboreal nests, cocoon-spinning species, Crematogaster sp., Kalahari, Vachellia erioloba 


\section{Introduction}

Ecosystem engineers alter their environment in such a way that it benefits themselves or, either directly or indirectly, other organisms by creating, modifying or maintaining habitats (Jones et al., 1997; Breitburg et al., 2010). Consequently, ecosystem engineers promote habitat heterogeneity and can affect patterns and processes at the individual, population and community level. Indeed, by increasing local habitat patchiness, ecosystem engineers can alter population dynamics and support different species compared with equivalent environments from which they are absent (Jones et al., 1997; Dangerfield et al., 1998). Autogenic ecosystem engineers alter the environment via their own physical structures (e.g. plants, mussels or biofilm-producing microbes) (Jones et al., 1997; Dangerfield et al., 1998). In contrast, allogenic ecosystem engineers, such as soil cast-creating earthworms, tree-felling elephants and dam-building beavers (Jones et al., 1997; Breitburg et al., 2010), transform materials from one physical state into another (Dangerfield et al., 1998).

In arboreal systems, there are many examples of allogenic herbivorous invertebrate ecosystem engineers, including leaf-tying, leaf-rolling and leaf-folding caterpillars, leaf miners and wood-boring beetles (Fukui, 2001; Lill and Marquis, 2003; Lima et al., 2013). The shelters that they create within trees are frequently used by other taxa as refuges against negative bottom-up (e.g. plant chemical defences) or top-down (e.g. predation) effects (Fukui, 2001). These shelters, through their provisioning of new physical structures and novel microhabitat conditions in trees, may influence the abundance, survival and distribution of other species, and can therefore shape local patterns of species diversity (Fukui, 2001; Lill and Marquis, 2003; Cornelissen et al., 2016).

Arboreal ants are canopy-dwelling invertebrates that form part of important protective antplant mutualisms in both temperate and tropical regions (Heil and McKey, 2003). In these regions, they structure a multitude of biotic interactions (Moreau et al., 2006) and can be 
ecologically dominant and diverse. Arboreal ants use a wide variety of structures as nesting sites (Beattie and Hughes, 2002). These include plants structures such as specialized thorn domatia (Campbell et al., 2013a), other domatia in hollow stems, leaf pouches, petioles (Heil and McKey, 2003), and natural plant cavities (Dejean et al., 2012), as well as structures created by other organisms, such as leaf shelters constructed by lepidopteran larvae (Nakamura and Ohgushi, 2003). These structures serve many functions, including the provision of favourable conditions for rearing brood, sheltering the queen and providing refuges for workers against abiotic environmental conditions or natural enemies (Blüthgen and Feldhaar, 2010). In some cases, the structures that house arboreal ants can be considered ecosystem engineered structures if these structures are created, modified or maintained by other organisms and are able to ameliorate abiotic stress for the ants, provide ants with protection from natural enemies or increase ant survivorship (Cornelissen et al., 2016).

In this study, we report on the use by arboreal ants and other invertebrates of the empty cocoons of the economically important silk moth species, Gonometa postica Walker 1855 (Fig. 1) (Hartland-Rowe, 1992; Veldtman et al., 2002, 2007). The larvae of G. postica forage on the foliage of host trees for approximately two months before spinning cocoons (HartlandRowe, 1992). During foraging G. postica is involved in direct antagonistic interactions with arboreal ants (chiefly Crematogaster sp.); the ants display aggressive behaviour towards foraging G. postica larvae and remove the larvae from trees (Campbell et al., 2013b). This behaviour may be contingent on the presence of scale insects (e.g. Styrsky and Eubsnks, 2007).

However, we document here that this negative ant-caterpillar interaction can be followed by an indirect positive interaction, where empty $G$. postica cocoons serve as ant sheltering and nesting sites (similar to thorn domatia), potentially protecting ants and other invertebrates against environmental extremes and natural enemies by creating a unique, sheltered 
environment. Therefore, the empty cocoons can be considered autogenic ecosystem engineered structures, which create a new abiotic state that increases habitat heterogeneity in trees (Lill and Marquis, 2003; Cornelissen et al., 2016). Thus, this study examines, for the first time, the ecological function of empty G. postica cocoons as potential nests and shelters for arboreal ants and other invertebrates.

The aims of this study were to first characterise the patterns of ant species occurrence and co-occurrence within cocoons and trees. Second, we assessed whether ant species presence and abundance within cocoons is affected by cocoon characteristics. Good evidence exists that nest site (e.g. domatia) selection for arboreal ants is influenced by nest architecture (Fincke, 1999; Thomas, 2002; Campbell et al., 2013a). We thus examined how cocoon characteristics (e.g. cocoon length and width, and cocoon hole type) along with other variables (e.g. cocoon aspect, time of day sampled and the presence of other invertebrates in the cocoons) affected 1) ant species presence and 2) ant abundance. Last, we tested whether ant species presence and abundance is mediated by the presence of scale insects. These produce liquid food rewards for ants in return for protection against natural enemies (Heil and McKey, 2003; Gibbs and Cunningham, 2009) and may mediate arboreal ant distributions and behaviour towards herbivores (Gibbs and Cunningham, 2009). Therefore, we related ant species abundance and occurrence within cocoons to the presence of scale insects on the trees, the incidence of ants tending scale insects and the time of day that the observations were made. 


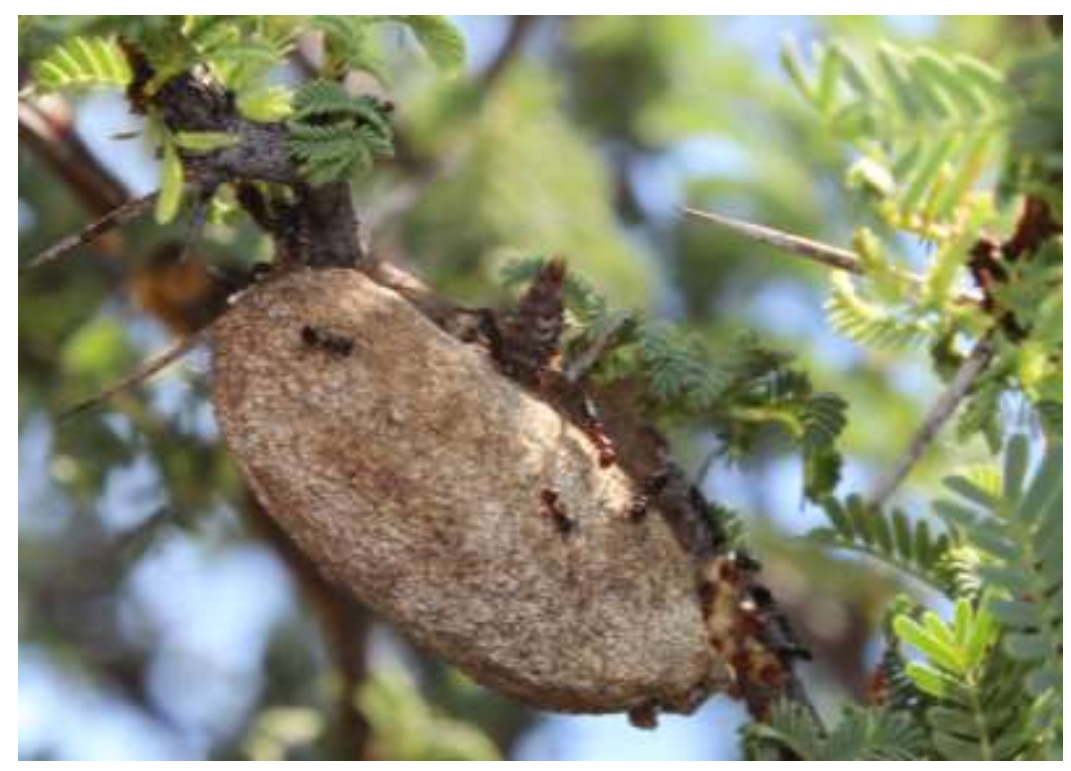

Fig. 1. An emerged Gonometa postica cocoon and associated ants on Vachellia erioloba. Scale insects are also visible on the bottom right of the twig. Photograph: Isabelle Buyens.

\section{Methods}

\subsection{Gonometa postica}

Gonometa postica is one of two indigenous silk moth species in southern Africa. The species has been extensively harvested, though little is known its biology (Veldtman et al., 2002). It occurs mainly in northern areas of South Africa but also in Namibia, Botswana and East Africa (Raath et al. unpublished data). The life cycle of Gonometa species is complex, characterised by two generations per year, one in early spring (September) and the other in mid-summer (December-January) (Delport, 2006; Veldtman et al., 2007). Their populations are considered to be eruptive, reaching very high densities over large areas during outbreak periods. It is unclear whether population eruptions occur after populations are exposed to ideal conditions or if eruptions are initiated through the dispersal of individuals that belonged to previously eruptive populations (Delport, 2006). Eruptions have also been observed following periods of drought, possibly because drought conditions are unfavourable for larval 
parasites (Hartland-Rowe, 1992). In contrast, large population crashes have been observed after heavy periods of rainfall. Therefore, G. postica displays sporadic and unpredictable population outbreaks, and high spatial and temporal variability in population size and extent (Veldtman et al., 2007).

\subsection{Sampling}

Fieldwork was conducted over an area of approximately $5 \mathrm{~km}^{2}$ on the Oppiknoppi Guest

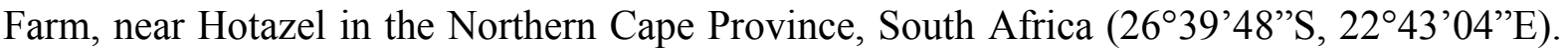
The farm lies in the Kalahari, which is an arid component of the savanna biome (Knobel and Bredenkamp, 1999). The area receives about $400 \mathrm{~mm}$ rainfall p.a. and is characterised by deep, sandy soils. Dominant trees at the site, Vachellia erioloba, Senegalia mellifera and Boscia albitrunca, were sparsely scattered between a variety of grass and shrub species.

Gonometa postica cocoons were collected from V. erioloba trees in December 2014 and January 2015. Vachellia erioloba, one of G. postica's main host plants in southern Africa, was the only plant species on which cocoons were found in abundance (Hartland-Rowe, 1992; Veldtman et al., 2002, 2007). None of the cocoons was occupied by G. postica at the time of sampling, and cocoons were probably from a previous outbreak of the species, two years prior to the sampling period (2012/2013). Sampling was conducted in the mornings between 5:30 and 12:00, and in the late afternoon between 14:00-18:00. All sampled trees were located at more than $20 \mathrm{~m}$ from farm roads to minimise road effects. Trees were sampled on transects of variable lengths. For each transect, a starting point (focal tree) was randomly selected and sampled (Fig. A.1. in Supplementary Material). Thereafter, the two nearest neighbouring trees were also selected and sampled. Trees were sampled in such a way that the nearest neighbour of one focal tree was not the nearest neighbour of another focal tree. Thereafter, the next focal tree (located within a $90^{\circ}$ angle in the direction of the transect 
and at least $10 \mathrm{~m}$ away from the previous focal tree) was sampled along with its two nearest neighbours. This selection procedure was repeated by walking along the length of the transect (see Catana, 1963). Only trees ranging in height from $1.5 \mathrm{~m}$ to $5 \mathrm{~m}$ were sampled because no cocoons were found on trees less than $1.5 \mathrm{~m}$ in height and it was not possible to accurately count and sample cocoons on trees exceeding $5 \mathrm{~m}$.

The cover (present on $0 \%,<1 \%, 0-10 \%, 10-15 \%, 15-20 \%, 20-25 \%, 25-30 \%, 30-40 \%$ and $>40 \%$ of branches) of scale insects per tree was visually estimated, and whether scale insects were tended by ants (i.e. the presence and absence of scale insect-ant interactions) was recorded. If there was tending, the morphospecies of ants that were tending scale insects were recorded. Vachellia erioloba can form swollen thorn domatia. These form part of protective ant-plant interactions (Heil and McKey, 2003): the plants provide ants with specialised, preformed nesting sites (domatia) in return for protection against a range of herbivores. Therefore, the presence of swollen thorn domatia (see Campbell et al., 2013a) was also recorded for each tree.

Every G. postica cocoon that could be reached by hand or with a $1 \mathrm{~m}$ pole was collected from sampled trees. For each collected cocoon, aspect (i.e. whether the cocoon was collected from the north or south sides of the host tree) and the time of collection were recorded. Cocoons that contained one or more small holes (mean diameter $\pm \mathrm{SD}=2.68 \pm 1.71 \mathrm{~mm}$ ) were categorized as parasitized, although we acknowledge the possibility that some of these small holes may have been created or modified by the ants themselves (e.g. see Federle et al., 2001). The majority of $G$. postica parasites are wasps (Hymenoptera, in the families Ichneumonidae, Chalcididae, Eurytomidae, Perilampidae and Eupelmidae) while some belong to the Diptera within the family Tachinidae (see Veldtman et al., 2004). Cocoons containing a larger hole (mean diameter $=6.72 \pm 2.12 \mathrm{~mm}$ ) towards the apex of the cocoon (with a characteristic three-fold split) were considered to be "emerged" (i.e. cocoons from 
which fully-developed moths had emerged). Cocoons that contained both a large hole towards their apex and small holes were considered as emerged with secondary holes (i.e. holes potentially created by ants or other invertebrates following moth emergence).

Sampled cocoons were frozen to kill invertebrate occupants. The length and width of each collected cocoon were measured using a digital calliper, and the cocoons were cut open and the abundance, morphospecies and life stage of ants (adults, juveniles and eggs) within each cocoon recorded. Reference specimens of the morphospecies were collected from all sampled cocoons. The presence and identity of other invertebrates, broadly classified as Araneae (spiders), Coleoptera (beetles) or Lepidoptera (caterpillars), within the cocoons were also recorded.

\subsection{Statistical analyses}

Ant abundance data were both zero-inflated and overdispersed. Data were therefore analysed using hurdle models, which involve two analyses (Rose et al., 2006). One analysis tests for trends in the positive (count) data with a linear model, whereas the other compares zeros to non-zeros with a binary model. All hurdle models were run as generalized linear mixed effects models (hurdle GLMMs), with tree identity as a random effect to account for multiple cocoons being collected from some trees. A truncated negative binomial distribution with a log-link function was fitted to all analyses on count data to correct for overdispersion (Rose et al., 2006), and all binary models were fitted using a binomial distribution and the logit-link function.

To ascertain if ants were selecting G. postica cocoons based on cocoon characteristics, a hurdle GLMM was run to test whether ant morphospecies abundances and presence-absence within cocoons were influenced by cocoon aspect, cocoon length and width, and cocoon hole type. Also included as predictors were the occurrence of other invertebrates within the cocoons and time of day that the cocoons were sampled (with a quadratic term), as these may 
have affected ant abundance or occurrence. Most morphospecies were infrequently recorded

within cocoons. Therefore, this analysis was only conducted for Crematogaster sp. 1. A third GLMM hurdle model was run to test whether ant abundance and occurrence within cocoons was related to the presence of scale insects on the trees, the presence of ants tending scale insects and the time of day that the observations were made. For this analysis, total ant abundance was used as response variable. No cocoon characteristics (mentioned above) were included as predictors for this analysis.

For each component of the hurdle models, predictor variable selection was done by forward stepwise regression, which selected the best models based on model AIC scores. Data were analysed in R v.3.0.2 (R Core Team, 2013) using the glmmADMB package.

\section{Results}

\subsection{Morphospecies occurrence within trees and $\mathrm{G}$. postica cocoons}

Thorn domatia were absent from the majority $(n=173)$ of the $V$. erioloba trees $(n=197)$ surveyed in this study, and when thorn domatia were present G. postica cocoons were also present. The mean number of $G$. postica cocoons collected per tree was $5.9 \pm 4.1$ (mean \pm SD). Of these, $2.6 \pm 2$ were occupied by ants. These are not the true mean value because only cocoons that could be reached by hand or through the use of a $1 \mathrm{~m}$ pole were collected. Cocoons at the very tops of the trees (which could not be reached) were not collected. Five ant species, including two Crematogaster species were identified in the collected cocoons (Fig. 2; Table 1). Cataulacus sp. and Crematogaster sp. 1 were the most abundant ant species per cocoon on average (Fig. 2a); however, the highest total mean ant abundance was observed when the two Crematogaster species co-occupied cocoons. Crematogaster sp. 1 had the highest number of brood within cocoons (Fig. 2b) followed by Cataulacus sp. and the 
Crematogaster spp. co-occupants. No brood was found in cocoons occupied by Crematogaster sp. 2 and Nesomyrmex sp.
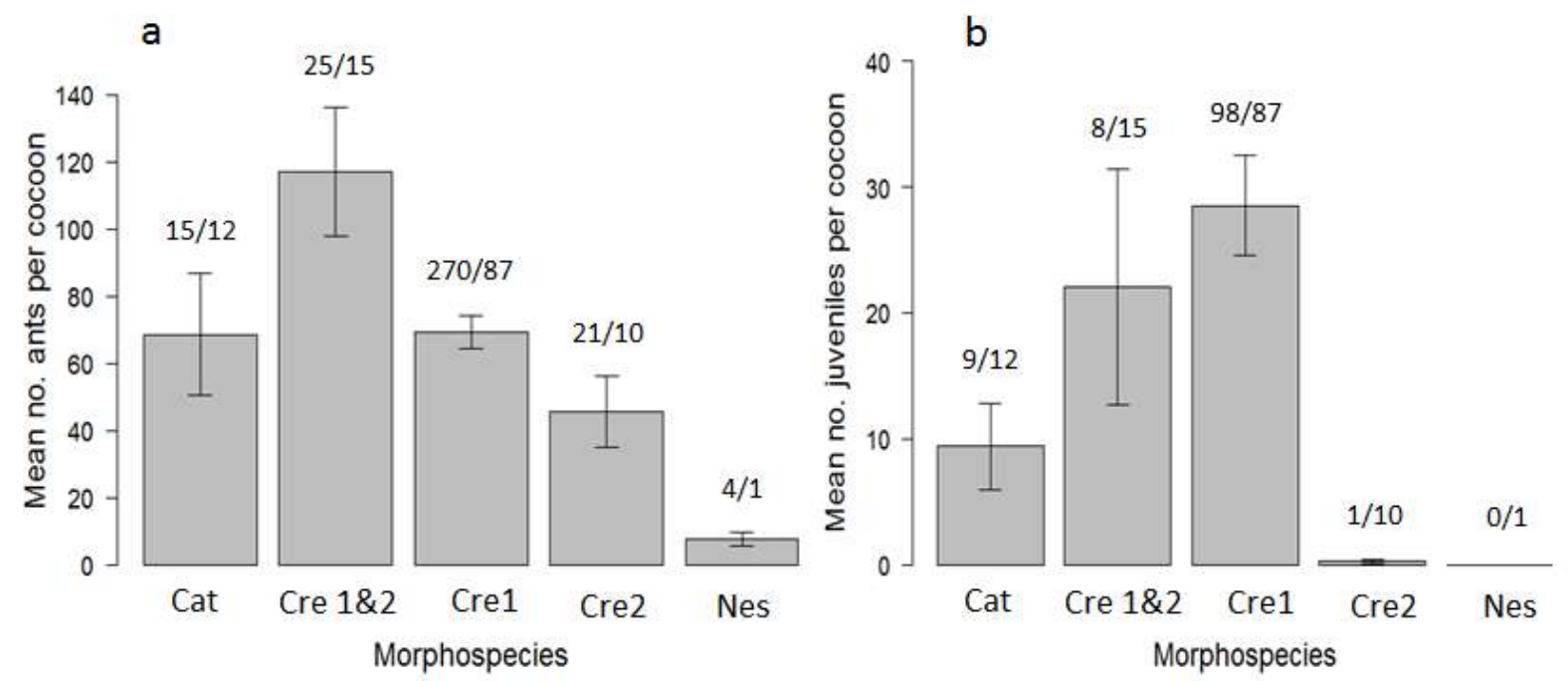

Fig 2. a) Mean ( \pm SE) abundance of ant morphospecies per ant-occupied Gonometa postica cocoon $(\mathrm{n}=336$ cocoons). b) Mean ( \pm SE) abundance of brood ants for Cataulacus sp. (Cat) Crematogaster sp. 1 (Cre1), Crematogaster sp. 2 (Cre2), Crematogaster spp. co-occupants (Cre 1\&2) and Nesomyrmwx sp. (Nes). The number of cocoons and trees $(\mathrm{n} / \mathrm{n})$ from which each morphospecies and juveniles morphospecies was recorded is indicated above the bars.

Trees with cocoons were most commonly occupied by a single ant species ( $n=73$ of 124 , $c f .59 \%)$, with fewer of these trees co-occupied by two species $(\mathrm{n}=52$ of $124, c f .42 \%)$ and only four of these trees co-occupied by three ant species (Table 1). Crematogaster sp. 1 was dominant, occupying cocoons on 87 trees $(c f .70 \%)$ in total of which $66(c f .53 \%)$ of the trees were exclusively occupied by this species (without any other ant species).

Crematogaster sp. 1 was also the most commonly encountered ant species within $G$. postica cocoons, occurring in 270 ( $c f .80 \%)$ of the 336 ant-occupied cocoons. On average, this species occurred in $2.1 \pm 2.4$ cocoons per tree. The remaining morphospecies each occurred in less than 25 of the sampled cocoons (Table 1), although the two Crematogaster morphospecies occurred together within 25 of the 336 ant-occupied cocoons. Nesomyrmex 
sp. and Camponotus sp. were rarely recorded in cocoons on the trees, occupying $n=4$ and $n$ $=1$ of the total 336 ant-occupied cocoons respectively (Table 1$)$. About half $(c f .52 \%)$ of the cocoons sampled $(\mathrm{n}=366$ of $\mathrm{n}=702)$ were unoccupied by ants; however, $88(c f .24 \%)$ of these unoccupied cocoons were occupied by other invertebrates (spiders, caterpillars and/or beetles). Crematogaster sp. 1 most often co-occurred in cocoons with other invertebrates ( $\mathrm{n}=$ 37 of 702$)$.

Table 1. The number of trees $(n=124)$ on which each ant morphospecies occurred, and the number of trees that were exclusively occupied by the ant species (i.e. other ant species were not recorded on the tree). Cocoons occupied: total number of cocoons $(n=702)$ occupied by each ant morphospecies. Shared occupancy with other invertebrates of 1) trees: the number of trees in which both cocoons occupied by the ant species and cocoons occupied exclusively by other invertebrates were recorded; and 2) cocoons: the number of cocoons that were cooccupied by the ant morphospecies and other invertebrates. Ants occupied a total of 336 cocoons, co-occupied 25 cocoons with other ant species and co-occupied 41 cocoons with other invertebrates. A total of 194 cocoons contained neither ants nor other invertebrates

\begin{tabular}{lccccc}
\hline Morphospecies & Trees occupied & $\begin{array}{c}\text { Cocoons } \\
\text { occupied }\end{array}$ & $\begin{array}{c}\text { Shared occupancy with other } \\
\text { non-ant invertebrates }\end{array}$ \\
\hline & Total & Exclusively & Total & Trees & Cocoons \\
\hline Crematogaster sp. 1 (Myrmicinae) & 87 & 66 & 270 & 27 & 37 \\
Crematogaster sp. 2 (Myrmicinae) & 10 & 4 & 21 & 3 & 0 \\
Crematogaster sp. 1 and Crematogaster & 15 & 1 & 25 & 5 & 3 \\
sp. 2 co-occupants & 12 & 1 & 15 & 5 & 1 \\
Cataulacus sp. (Myrmicinae) & 1 & 1 & 1 & 0 & 0 \\
Camponotus sp. (Formicinae) & 1 & 0 & 4 & 0 & 0 \\
Nesomyrmex sp. (Formicinae) & & &
\end{tabular}

3.2. The effect of cocoon characteristics and scale insects on ant abundance and occurrence

Due to most morphospecies being only infrequently recorded within cocoons, analyses testing the effect of cocoon characteristics on ant abundance and presence-absence were only conducted for Crematogaster sp. 1 (Table A.1 in Supplementary Material). The analyses 
yielded similar results to those when all ant species were analysed together (Table A.2 in Supplementary Material). Cocoons containing only small holes, had higher abundances of Crematogaster sp. 1 than cocoons containing only emergence holes $(\mathrm{p}=0.031$; Table A.1). Crematogaster sp. 1 was significantly more abundant in cocoons from which other invertebrates (i.e. spiders, caterpillars and beetles) were absent $(\mathrm{p}<0.001)$. The abundance of Crematogaster sp. 1 was also positively affected by cocoon width ( $\mathrm{p}<0.01$; Table A.1), while species occurrence was negatively related to cocoon length $(p=0.033$; Table A.1).

Both Crematogaster species were most frequently observed tending scale insects but tending by the Camponotus species was also observed on some of the trees. The presence of scale insects on $V$. erioloba trees, the incidence of ants tending scale insects and the time of day that the cocoons were sampled were either not included in the minimal adequate models or had no significant effect on ant abundance in $G$. postica cocoons (Table A.3 in Supplementary Material). However, there was a higher incidence of ant presences in cocoons if scale insects were present on the tree.

\section{Discussion}

Our results demonstrated a novel ecological role of a cocoon-spinning lepidopteran species, with ants and other invertebrates using $G$. postica cocoons as nesting sites and for shelter. Empty G. postica cocoons can therefore be considered as ecosystem engineered structures (see Lill and Marquis, 2003; Lima et al., 2013; Cornelissen et al., 2016) because they create a new abiotic state within trees that is different from the unmodified abiotic conditions. Arboreal ants are territorially dominant and often occur on myrmecophytes, which they protect from herbivores in exchange for food rewards or nesting sites (Heil and McKey, 2003; Palmer et al., 2008; Stanton and Palmer, 2011; Campbell et al., 2013b). Thorn domatia were rarely recorded on the $V$. erioloba individuals sampled in this study; however, ants appeared to secondarily occupy and house their brood within vacant $G$. postica cocoons. This 
was surprising because arboreal ant species belonging to the Crematogaster genus have been observed to behave aggressively towards G. postica on $V$. erioloba by removing larvae from the trees (Campbell et al., 2013b). This suggests that the direct negative interaction between ants and G. postica is followed by an indirect commensal interaction, where (abandoned) $G$. postica cocoons benefit ants who gain shelter and nesting sites from the cocoons.

\subsection{Ant morphospecies occurrence and co-occurrence in trees and cocoons}

Certain ant species are known to nest exclusively in myrmecophytes (Palmer et al., 2000; Heil and McKey, 2003), occupying individual trees in the absence of other ant species. In some cases different species share a myrmecophyte, coexisting with other ant species in the same tree (Raine et al., 2004; Campbell et al., 2013a; Campbell et al., 2015). In this study, trees and cocoons were predominantly occupied by Crematogaster sp. 1, but in some cases simultaneously by multiple ant species. Crematogaster species frequently dominate the trees in which they nest and are very territorial in colony defence (Stanton and Palmer, 2011). However, in this study, shared occupancy of cocoons was observed for Crematogaster sp. 1 and Crematogaster sp. 2. Ant co-occupancy of nest sites (parabiosis) has also been reported elsewhere, e.g. from ant gardens in the Neotropics and Paleotropics (Orivel et al., 1997). Disadvantages to sharing shelters include decreased fitness through reduced pupal mass (Lill et al., 2007) and increased competition during foraging which leads to decreased food retrieval (Menzel et al., 2014). However, co-occupancy of nests by ant species could also enhance defence against mutual enemies (Sagata et al., 2010), and in ant gardens, two ant species may even forage together or feed one another (Menzel and Blüthgen, 2010). Moreover, ant species may benefit from co-occupancy through shared pheromone trails leading to food sources. Whether the relationship between the Crematogaster spp. in this study is mutualistic remains to be determined. 
Larger trees appeared to have more cocoons and ants; however, approximately half of all cocoons were unoccupied by ants or other invertebrates (see also Sagata et al., 2010; Campbell et al., 2015). While this could be due to low cocoon occupancy (perhaps because ants use the cocoons opportunistically as shelter and nesting sites); it may also be because ants migrate between shelters to track microclimates (Jones and Oldroyd, 2007), or due to recent changes in colony sizes (Palmer, 2003).

\subsection{Morphospecies abundance and occurrence in cocoons as a function of cocoon} characteristics

Ant colonies can select nests based on the quality of each nesting site relative to others (Thomas, 2002). Of the occupied G. postica cocoons, ant abundance and occurrence were highest and most apparent in cocoons that contained only parasite holes (the smallest hole types within the cocoons). Similarly, Pratt and Pierce (2001) found that the cavity-dwelling ant species, Leptothorax curvispinosus, preferred cavities that had small entrance holes. A preference for cocoons with smaller holes could be because these cocoons show greater thermal buffering and higher humidity levels (see Jones and Oldroyd, 2007). Indeed, desiccation (Hood and Tschinkel, 1990) and heat (Roces and Núñez, 1989) are important stresses for ants, especially in arid environments. Cocoons with smaller holes may also provide refuge from competitors and predators to the ants and their brood (Blüthgen and Feldhaar, 2010), because nests with smaller entrance holes can be more effectively defended (Palmer, 2003).

Ant abundance was greater in wider cocoons, in agreement with studies that show that domatium size constrains colony size (Thomas, 2002; Campbell et al., 2013a). Larger nests can support more individual ants and brood (Campbell et al., 2013a). Conversely, ants were less likely to occur in longer cocoons, indicating that nest selection is also influenced by nest 
shape, which can affect microclimatic parameters such as the amount of solar radiation reaching the nest surface (Hubbard and Cunningham, 1977).

\subsection{Scale insect presence}

Ant occurrence in cocoons was positively related to the presence of scale insects. Honeydew-producing homopterans play an important role in structuring arboreal ant communities (Blüthgen et al., 2004; Styrsky and Eubanks, 2007) because they represent a key resource for the ants (Davidson et al., 2003). Both Crematogaster species were the most commonly encountered species tending the scale insects on the trees in this study, matching observations from other studies (Campbell et al., 2013b). This is further supported by observations that dominant ant species usually monopolize honeydew sources, making their co-occurrence with other scale insect-tending ant species rare (Blüthgen et al., 2004). Moreover, when scale insects were present on the trees, ants were nearly always observed tending them. These results suggest that on top of cocoon characteristics, the presence of scale insects on trees is another important factor for nest site selection by arboreal ants.

\subsection{Conclusion}

Our results suggest that $G$. postica cocoons increase tree structural complexity to the benefit of arboreal invertebrates. The fact that the cocoons constitute a habitat utilized by other species suggests that G. postica is indeed an autogenic ecosystem engineer (Lill and Marquis, 2003; Wright and Jones, 2006; Lima et al., 2013). Ecosystem engineering effects can occur at fine and broad scales and for short to long time periods (Wright and Jones, 2006). Due to the sporadic nature of Gonometa populations through space and time (Veldtman et al., 2007), the ecosystem engineering effect that the cocoons provide will likely vary spatially and temporally, occurring in an area in some years and not in others. The exact spatial scale at which G. postica cocoons are functioning as nest sites and shelters for arboreal invertebrates 
is unknown. However, this phenomenon has been observed in the region of, but at significant distances from, the study area (> $50 \mathrm{~km}$, pers. obs. MJR \& MG) and in Namibia (> $600 \mathrm{~km}$ from the study area, pers. obs. HC). Moreover, Gonometa postica cocoons persist for at least two years within this environment, providing shelter and nest sites for ants and other invertebrates from the time of moth emergence until the cocoon degrades or falls off the tree. What remains to be determined is whether the cocoons significantly impact populations of ants and other invertebrates that utilize the structures, or whether these empty cocoons only function as opportunistic shelters and nest sites.

The shelter and nesting site function of G. postica cocoons could have implications for the harvesting of cocoons from the wild. Currently, silk industries in southern Africa are mainly reliant on harvesting empty G. postica cocoons or the pupal stage of the species (Veldtman et al., 2007). Such harvesting could impact upon the multiple species interactions occurring within these arboreal systems. Removal of cocoons could, for example, lead to increased myrmecophyte defoliation (or even mortality; see Moraes and Vasconcelos, 2009) of $V$. erioloba through the breakdown of mutualisms (Palmer et al., 2008). Ant-scale insect associations may also be sensitive to cocoon harvesting (see Feldhaar et al., 2000).

Therefore, depending on the spatial extent and permanence of the effect of the presence of empty $G$. postica on arboreal invertebrates, silk industries may have to be limited to harvesting a proportion of cocoons per tree. If cocoon collection cannot be regulated to maintain the ecological interactions in these arboreal systems, silk industries should focus on rolling out and improving semi-captive and artificial rearing techniques (Ngoka et al., 2008.). That way both $G$. postica populations and the species' greater ecological role can be maintained. 


\section{Acknowledgements}

The authors would like to thank Pieter and Tanya Grové at Oppiknoppi Guest Farm (Belville Farm) for allowing us to use their farm for this research. Thank you to the University of Pretoria (RDP funding to Michelle Greve), the South African National Research Foundation (grant number: 101515) and the South African National Biodiversity Institute. Lastly, thank you to Northern Cape Nature Conservation for issuing research and collecting permits (NCU 4640714, FAUNA 424/2/2014 and FAUNA: 1736/2014).

\section{References}

Beattie, A.J., and Hughes, L., 2002. Ant-plant interactions. In: Herrera CM, Pellmyr O (eds) Plant-animal interactions: an evolutionary approach. Blackwell Science, Oxford, pp $211-235$.

Blüthgen, N., Stork, N.E. and Fiedler, K., 2004. Bottom-up control and co-occurrence in complex communities: honeydew and nectar determine a rainforest ant mosaic. Oikos $106,344-358$.

Blüthgen, N. and Feldhaar, H., 2010. Food and shelter: how resources influence ant ecology. In: Lach L, Parr C, Abbott K. eds. Ant ecology. Oxford: Oxford University Press, $115-136$.

Breitburg, D.L., Crump, D.C., Dabiri, J.O. and Gallegos, C.L., 2010. Ecosystem engineers in the pelagic realm: alteration of habitat by species ranging from microbes to jellyfish. Integrative and Comparative Biology 50, 188-200.

Campbell, H., Townsend, L.R., Fellowes, M.D.E. and Cook, J.M., 2013a. Arboreal thorndwelling ants coexisting on the savannah ant-plant, Vachellia erioloba, use domatia morphology to select nest sites. Insectes Sociaux 60, 373-382. 
Campbell, H., Townsend, L.R., Fellowes, M.D.E. and Cook, J.M., 2013b. Thorn-dwelling ants provide antiherbivore defence for camelthorn trees, Vachellia erioloba, in Namibia. African Journal of Ecology 51, 590-598.

Campbell, H., Fellowes, M.D.E. and Cook, J.M., 2015. The curious case of the camelthorn: competition, coexistence, and nest-site limitation in a multispecies mutualism. The American Naturalist 186, E173-E181.

Catana, A.J. Jr., 1963. The wandering quarter method of estimating population density. Ecology 44, 349-360.

Cornelissen, T., Cintra, F. and Santos, J.C., 2016. Shelter-Building insects and their role as ecosystem engineers. Neotropical Entomology 45, 1-12.

Dangerfield, J.M., McCarthy, T.S. and Ellery, W.N., 1998. The mound-building termite Macrotermes michaelseni as an ecosystem engineer. Journal of Tropical Ecology 14, $507-520$.

Davidson, D.W., Cook, S.C., Snelling, R.R. and Chua, T.H., 2003. Explaining the abundance of ants in lowland tropical rainforest canopies. Science 300, 969-972.

Dejean, A., Delabie, J.C.H., Cobara, B., Azemar, F., Groc, S., Orivel, J. and Leponse, M., 2012. The ecology and feeding habits of the arboreal trap-jawed ant Daceton armigerum. PLoS ONE 7, e37683.

Delport, W., 2006. Population genetic inference of demographic processes in the African Wild Silk Moth, Gonometa postica (Lasiocampidae). $\mathrm{PhD}$ thesis, University of Pretoria, South Africa.

Federle, W., Brainerd, E.L., McMahon, T.A. and Hölldobler, B., 2001. Biomechanics of the movable pretarsal adhesive organ in ants and bees. Proceedings of the National Academy of Science 98, 6215-6220. 
Feldhaar, H., Fiala, B., bin Hashim, R. and Maschwitz, U., 2000. Maintaining an ant-plant symbiosis: secondary polygyny in the Macaranga triloba-Crematogaster sp. association. Naturwissenschaften 87, 408-411.

Fincke, O.M., 1999. Organisation of predator assemblages in neotropical tree holes: effects of abiotic factors and priority. Ecological Entomology 24, 13-23.

Fukui, A., 2001. Indirect interactions mediated by leaf shelters in animal-plant communities. Population Ecology 43, 31-40.

Gibbs, H. and Cunningham, S.A., 2009. Does the availability of arboreal honeydew determine the prevalence of ecologically dominant ants in restored habitats? Insectes Sociaux 56, 405-412.

Hartland-Rowe, R., 1992. The biology of the wild silkmoth Gonometa rufobrunnea Aurivillius (Lasiocampidae) in northeastern Botswana, with comments on its potential as a source of wild silk. Botswana Notes and Records 24, 123-133.

Heil, M. and McKey, D., 2003. Protective ant-plant interactions as model systems in ecological an evolutionary research. Annual Review of Ecology, Evolution and Systematics 34, 425-453.

Hood, W.G. and Tschinkel, W.R., 1990. Desiccation resistance in arboreal and terrestrial ants. Physiological Entomology 15, 23-25.

Hubbard, M.D. and Cunningham, W.G., 1977. Orientation of mounds of the ant Solenopsis invicta (Hymenoptera, Formicidae, Myrmicinae). Insectes Sociaux 24, 3-7.

Jones, C.G., Lawton, J.H. and Shachak, M., 1997. Positive and negative effects of organisms as physical ecosystem engineers. Ecology 78, 1946-1957.

Jones, J.C. and Oldroyd, B.P., 2007. Nest thermoregulation in social insects. Advances in Insect Physiology 33, 153-191. 
Knobel, J. and Bredenkamp, G., 1999. The magnificent natural heritage of South Africa. Sunbird Publishers, Roggebaai, pp. 10-25.

Lill, J.T. and Marquis, R.J., 2003. Ecosystem engineering by caterpillars increases insect herbivore diversity on white oak. Ecology 84, 682-690.

Lill, J.T., Marquis, R.J., Walker, M.A. and Peterson, L., 2007. Ecological consequences of shelter sharing by leaf-tying caterpillars. Entomologia Experimentalis et Applicata $124,45-53$.

Lima, V.O., Demite, P.R., Vieira, C., Feres, R.J.F. and Romero, G.Q., 2013. Contrasting engineering effects of leaf-rolling caterpillars on a tropical mite community. Ecological Entomology 38, 193-200.

Menzel, F. and Blüthgen, N., 2010. Parabiotic associations between tropical ants: equal partnership or parasitic exploitation? Journal of Animal Ecology 79, 71-81.

Menzel, F., Kriesell, H. and Witte, V., 2014. Parabiotic ants: the costs and benefits of symbiosis. Ecological Entomology 39, 436-444.

Moraes, S.C. and Vasconcelos, H.L., 2009. Long-term persistence of a Neotropical ant-plant population in the absence of obligate plant-ants. Ecology 90, 2375-2383.

Moreau, C.S., Bell, C.D., Vila, R., Archibald, S.B. and Pierce, N.E., 2006. Phylogeny of the ants: diversification in the age of angiosperms. Science 312, 101-104.

Nakamura, M. and Ohgushi, T., 2003. Positive and negative effects of leaf shelters on herbivorous insects: linking multiple herbivore species on a willow. Oecologia 136, $445-449$.

Ngoka, B.M., Kioko, E.N., Raina, S.K., Mueke, J.M. and Kimbu, D.M., 2008. Semi-captive rearing of the African Wild Silkmoth Gonometa postica (Lepidoptera: Lasiocampidae) on an indigenous and a non-indigenous host plant in Kenya. International Journal of Tropical Insect Science 27, 183-190. 
Orivel, J., Errard, C. and Dejean, A., 1997. Ant Gardens: interspecific recognition in parabiotic ant species. Behavioural Ecology and Sociobiology 40, 87-93.

Palmer, T.M., Young, T.P., Stanton, M.L. and Wenk, E., 2000. Short-term dynamics of an Acacia ant community in Laikipia, Kenya. Oecologia 123, 425-435.

Palmer, T.M., 2003. Spatial habitat heterogeneity influences competition and coexistence in an African acacia ant guild. Ecology 84, 2843-2855.

Palmer, T.M., Stanton, M.L., Young, T.P., Goheen, J.R., Pringle, R.M. and Karban, R., 2008. Breakdown of an ant-plant mutualism follows the loss of large herbivores from an African savanna. Science 319, 192-195.

Pratt, S.C. and Pierce, N.E., 2001. The cavity-dwelling ant Leptothorax curvispinosus use nest geometry to discriminate between potential homes. Animal Behaviour 62, 281287.

Raine, N.E., Gammans, N., Macfadyen, I.J., Scrivner, G.K. and Stone, G.N., 2004. Guards and thieves: antagonistic interactions between two ant species coexisting on the same ant-plant. Ecological Entomology 29, 345-352.

Roces, F. and Núñez, A., 1989. Brood translocation and circadian variation of temperature preference in the ant Camponotus mus. Oecologia 81, 33-37.

Rose, C.E., Martin, S.W., Wannemuehler, K.A. and Plikaytis, B.D., 2006. On the use of zeroinflated and hurdle models for modeling vaccine adverse event count data. Journal of Biopharmaceutical Statistics 16, 463-481.

Sagata, K., Mack, A.L. Wright, D.D. and Lester, P.J., 2010. The influence of nest availability on the abundance and diversity of twig-dwelling ants in a Papua New Guinea forest. Insectes Sociaux 57, 333-341.

Stanton, M.L. and Palmer, T.P., 2011.The high cost of mutualism: effects of four species of East African ant symbionts on their myrmecophyte host tree. Ecology 92, 1073-1082. 
Styrsky, J.D. and Eubanks, M.D., 2007. Ecological consequences of interactions between ants and honeydew-producing insects. Proceedings of the Royal Society of London B $274,151-164$.

Thomas, M.L., 2002. Nest site selection and longevity in the ponerine ant Rhytidoponera metallica (Hymenoptera, Formicidae). Insectes Sociaux 49,147-152.

Veldtman, R., McGeoch, M.A. and Scholtz, C.H., 2002. Variation in cocoon size in southern African wild silk moths: implications for sustainable harvesting. African Entomology $10,127-136$.

Veldtman, R., McGeoch, M.A. and Scholtz, C.H., 2004. Parasitoids of the southern African wild silk moths (Lepidoptera). African Entomology 12, 117-122.

Veldtman R., McGeoch M.A. and Scholtz C.H., 2007. Can life-history and defence traits predict the population dynamics and natural enemy responses of insect herbivores? Ecological Entomology 32, 662-673.

Wright, J.P. and Jones, C.G., 2006. The concept of organisms as ecosystem engineers ten years on: progress, limitations and challenges. BioScience 56, 203-209. 


\section{Supplementary Material.}

Table A.1. Results from the minimum adequate mixed effect hurdle models testing the effects of cocoon characteristics on (a) Crematogaster sp. 1 abundance ( $n=270$ cocoons, $n=88$ trees, $p<0.05$ ) and (b) Crematogaster sp. 1 presence-absence ( $\mathrm{n}=336$ cocoons, $\mathrm{n}=95$ trees, $\mathrm{p}<0.05)$ in Gonometa postica cocoons. Bold p-values indicate significant effects. Abbreviations: $\mathrm{P}=$ cocoons containing one or more small parasite holes; $\mathrm{E}=$ emerged cocoons and $\mathrm{ES}=$ emerged cocoons with secondary holes; $\operatorname{Pr}=$ other invertebrates present and $\mathrm{Ab}=$ other invertebrates absent

\begin{tabular}{|c|c|c|c|c|c|}
\hline a. Fixed effects & Level & Estimate & SE & $\mathrm{z}$ value & p-value \\
\hline (Intercept) & - & 2.434 & 0.376 & 6.470 & $<0.001$ \\
\hline Width & - & 0.097 & 0.019 & 5.090 & $<0.001$ \\
\hline Hole type & $\mathrm{P}>\mathrm{ES}>\mathrm{E}$ & - & - & - & 0.031 \\
\hline Time of day & - & -0.016 & 0.010 & -1.620 & 0.105 \\
\hline Other invertebrates & $\mathrm{Pr}>\mathrm{Ab}$ & - & - & - & $<0.001$ \\
\hline Random effect & SD & Variance & & & \\
\hline (1|Tree) & 0.471 & 0.222 & & & \\
\hline b. Fixed effects & Level & Estimate & SE & $\mathrm{z}$ value & p-value \\
\hline (Intercept) & - & -1.189 & 0.691 & -1.720 & 0.085 \\
\hline Length & - & -0.085 & 0.040 & -2.130 & 0.033 \\
\hline Random effect & SD & Variance & & & \\
\hline (1|Tree) & 3.124 & 9.757 & & & \\
\hline
\end{tabular}


Table A.2. Results from the minimum adequate mixed effect hurdle models testing the effects of cocoon characteristics on (a) overall ant abundance ( $\mathrm{n}=339$ cocoons, $\mathrm{n}=95$ trees, $\mathrm{p}<0.05)$ and (b) presence-absence ( $\mathrm{n}=702$ cocoons, $\mathrm{n}=124$ trees, $\mathrm{p}<0.05)$ in Gonometa postica cocoons. Bold $\mathrm{p}$-values indicate significant effects. Abbreviations: $\mathrm{P}=$ cocoons containing one or more small parasite holes; $\mathrm{E}=$ emerged cocoons and $\mathrm{ES}=$ emerged cocoons with secondary holes; $\mathrm{Pr}=$ other invertebrates present and $\mathrm{Ab}=$ other invertebrates absent; $\mathrm{N}$ $=$ north aspect and $\mathrm{S}=$ south aspect

\begin{tabular}{|c|c|c|c|c|c|}
\hline a. $\quad$ Fixed effects & Level & Estimate & $\mathrm{SE}$ & $\mathrm{z}$ value & p-value \\
\hline (Intercept) & - & 2.562 & 0.335 & 7.650 & $<0.001$ \\
\hline Width & - & 0.090 & 0.017 & 5.330 & $<0.001$ \\
\hline Hole type & $\mathrm{P}>\mathrm{ES}>\mathrm{E}$ & - & - & - & 0.018 \\
\hline Time of day & - & -0.016 & 0.009 & -1.680 & 0.094 \\
\hline Other invertebrates & $\mathrm{Pr}>\mathrm{Ab}$ & - & - & - & $<0.001$ \\
\hline Random effect & SD & Variance & & & \\
\hline (1|Tree) & 0.451 & 0.203 & & & \\
\hline b. Fixed effects & Level & Estimate & $\mathrm{SE}$ & $\mathrm{z}$ value & p-value \\
\hline (Intercept) & - & -1.189 & 0.691 & -1.720 & 0.085 \\
\hline Hole type & $\mathrm{P}>\mathrm{E}=\mathrm{ES}$ & - & - & - & $<0.001$ \\
\hline Time of day & - & -0.026 & 0.016 & -1.590 & 0.111 \\
\hline Other invertebrates & $\mathrm{P}>\mathrm{A}$ & - & - & - & $<0.001$ \\
\hline Length & - & 0.033 & 0.018 & 1.880 & 0.061 \\
\hline Aspect & $\mathrm{N}=\mathrm{S}$ & - & - & - & 0.086 \\
\hline Random effect & SD & Variance & & & \\
\hline (1|Tree) & 0.830 & 0.688 & & & \\
\hline
\end{tabular}


Table A.3. Results from the minimum adequate hurdle models, testing the effects of presence or absence of scale insects, the incidence of ants tending scale insects on the trees and time of day that sampling took place on (a) total ant abundance $(\mathrm{n}=99$ trees, $\mathrm{p}=0.033)$ and $(\mathrm{b})$ ant presence-absence $(\mathrm{n}=195$ trees, $\mathrm{p}<0.05)$ within all Gonometa postica cocoons per tree. Bold p-values indicate significant effects. Abbreviations: $\operatorname{Pr}=$ present and $\mathrm{Ab}=\mathrm{absent}$

\begin{tabular}{|c|c|c|c|c|c|}
\hline a. Variable & Level & Estimate & $\mathrm{SE}$ & $\mathrm{z}$ value & $\mathrm{p}$-value \\
\hline (Intercept) & - & 5.391 & 0.163 & 33.010 & $<0.001$ \\
\hline Ants tending scales & $\mathrm{Pr}=\mathrm{Ab}$ & - & - & - & 0.052 \\
\hline Time of day & - & -0.013 & 0.009 & -1.420 & 0.154 \\
\hline b. Variable & Level & Estimate & $\mathrm{SE}$ & $\mathrm{z}$ value & p-value \\
\hline (Intercept) & - & -1.334 & 0.362 & -3.680 & $<0.001$ \\
\hline Scale insects & $\mathrm{Pr}>\mathrm{Ab}$ & - & - & - & $<0.001$ \\
\hline Time of day & - & 0.038 & 0.020 & 1.940 & 0.052 \\
\hline
\end{tabular}




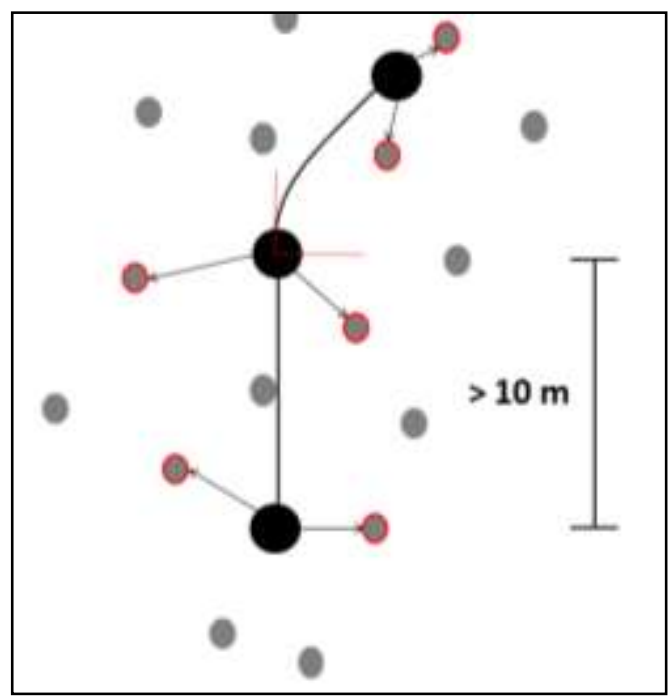

Fig A.1. Schematic diagram illustrating the tree sampling procedure. A focal tree (black dots) was randomly selected and sampled. The two nearest neighbouring trees (grey circles highlighted in red) were also selected and sampled such that the nearest neighbour of one focal tree was not the nearest neighbour of another focal tree. The next focal tree (located within a $90^{\circ}$ angle in the direction of the transect and at least $10 \mathrm{~m}$ away from the previous focal tree) was sampled along with its two nearest neighbours. 